\title{
Donald A. B. Lindberg: Inspiring Leader and Visionary in Biomedicine, Healthcare, and Informatics
}

\author{
Casimir A. Kulikowski \\ Department of Computer Science, Rutgers University, USA
}

\section{Summary}

Background: As Director of the US National Library of Medicine (NLM) for 30 years, Dr. Donald A. B. Lindberg was instrumental in bringing biomedical research and healthcare worldwide into the age of genomic and translational medicine through the informatics systems developed by the NLM. Lindberg opened free access and worldwide public dissemination of all the NLM's biomedical literature and databases, thus helping transform not only biomedical research like the Human Genome Project and its successors, but also the practices of medicine and healthcare internationally. Guiding, leading, and teaching-by-example at national, regional, and global levels of biomedical and healthcare informatics, lindberg helped coalesce a dynamic discipline that provides a foundation for the human understanding which promotes the future health of our world.

Objectives: To provide historical insight into the scientific, technological, and practical clinical accomplishments of Donald
Lindberg, and to describe how this led to contributions in the worldwide interdisciplinary evolution of informatics, and its impact on the biosciences and practices of medicine, nursing, and other healthcare-related disciplines.

Methods: Review and comment on the publications, scientific contributions, and leadership of Donald Lindberg in the evolution of biomedical and health informatics which anticipate the vision, scholarship, research in the field, and represent the deeply ethical humanism he exhibited throughout his life. These were essential in producing the informatics systems, such as the Unified Medical Language System (UMLS), MEDLINE, PubMed, PubMed Central, and ClinicalTrials.gov, which, together with NLM training programs and conferences, made possible the interactions among researchers and practitioners leading to the past quarter-century of rapid and dramatic advances in biomedical scientific inquiry and clinical discoveries, openly shared across the globe. Conclusion: Dr. Lindberg was a uniquely talented physician and pioneering researcher in biomedical and health informatics. As the main leader in developing and funding innovative informatics research for more than 30 years as Director of the National Library of Medicine, he helped bring together the most creative interdisciplinary researchers to bridge the worlds of biomedical research, education, and clinical practice. Lindberg's emphasis on open-access to the biomedical literature through publidy shared computer-mediated methods of search and inquiry are seen as an example of ethical scientific openness.

\section{Keywords}

Donald A.B. Lindberg, Interdisciplinary International Biomedical and Healthcare Informatics, UMLS, PubMed, Translational Medicine, ClinicalTrials.gov

Yearb Med Inform 2020:253-8

http://dx.doi.org/10.1055/s-0040-1701972

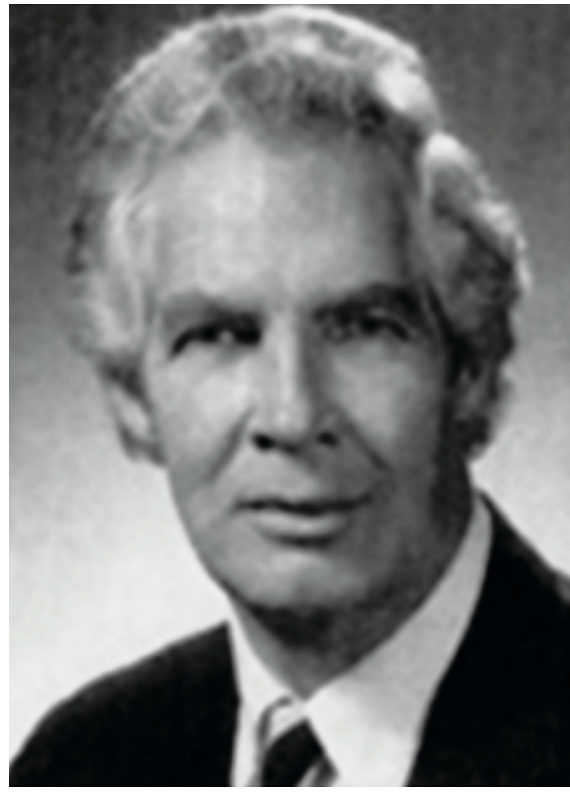

Lindberg, a Humanist Catalyzing Biomedical Research and Clinical Discovery through Knowledge-based Informatics

Donald A. B. Lindberg's worldwide influence on the development of medical informatics for over 50 years has been extensively recognized. The title of his obituary in the New York Times summarizes this well "Opened Medical Research to the World" [1]. This paper argues that through his pioneering research and subsequent leadership of the National Library of Medicine, he was instrumental in catalyzing a synthesis of the sciences, technologies, and humanistic visions so essential for the "human use of human beings" in the practices of medicine and healthcare that are being radically changed by the very technological revolution that Lindberg himself contributed to so significantly.

Don Lindberg's understated, but deeply knowledgeable demeanor, quiet common sense, and inimitable ability to bring together and convince powerful, insightful people with his arguments, all helped him stimulate and forge interdisciplinary teams of collaborators who worked together to produce the informatics methods and technologies which were key to the success of web-based, open, and free worldwide access to the indexed biomedical literature. These, in turn, were instrumental in making the results of the Human Genome Project and all other -omic 
and clinical translational research available - and likewise, the clinical discoveries that have followed from the deeper understanding and wider dissemination of biomedical and healthcare knowledge. This was primarily achieved through visionary informatics projects which produced systems that have become indispensable for researchers and clinicians alike. They include MEDLINE [2], PubMed [3], PubMed Central [4], the Visible Human Project [5], the Unified Medical Language System (UMLS) [6], TOXNET [7], and ClinicalTrials.gov [8,9] among the major systems that the National Library of Medicine (NLM) developed and freely opened to the world under Lindberg's direction. Lindberg's profound understanding and ethical approach to the practices of medicine and nursing, and the pursuit of biomedical knowledge and its informatics for the benefit of all persons everywhere regardless of gender, cultural, linguistic, or other backgrounds, was essential in helping biomedical and healthcare informatics grow with its own culture of open, shared research and practices exemplified in the codes of ethics of national and regional societies as well as IMIA itself $[9,10]$. Lindberg's leadership of the NLM helped promote and produce a very fertile mix of science, technology, and training that helped a wide range of academic groups around the world become very successful in bringing together like-minded practitioners, scientists, and technologists to help transform the field. The many bioinformatics projects and databases funded by NLM, and the founding of the National Center for Biotechnology Information (NCBI) [12] in 1989, made possible a very large number of the subsequent advances in genomic and other-omic sciences. The NLM, with the NCBI, continues to provide essential infrastructure and informatics support for major international data gathering and curation, and translational projects leading to the gradual emergence of translational medicine [13]. ClinicalTrials.gov was a major initiative supported by Lindberg that significantly enhanced the ease with which researchers can access, summarize, and analyze the results from clinical trials not only in the USA, but also in international sources $[8,9,14]$.
Lindberg was unparalleled in bringing people together professionally in biomedical and healthcare informatics, leading to the crystallization of the discipline. He was key to the formation of the American College of Medical Informatics in 1984 [15] and to the organization and leadership of the Fifth World Congress of Medical Informatics (MEDINFO 1986) held for the first time in the USA, in Washington, D.C. [16]. A few years later, in 1989, he led an effort to coalesce several of the diverse biomedical informatics groups in the USA to form the American Medical Informatics Association (AMIA), becoming the founding president [15 p. 55]. Lindberg's expansion of NLM support for university-based medical informatics training grants, and the NLM Associate Fellowship Program both trained many leaders in the informatics and library science communities. The Integrated Advanced Information Management System (IAIMS) program [17] was influential in helping build the discipline. As the first director of the National Coordination Office (NCO) for High Performance Computing and Communication in 1991 [18], Lindberg helped advance the technology behind the internet and its distributed communications and software systems. He led by example in demonstrating the critical role of computing in biomedical discovery and healthcare [19].

In the international arena, Don Lindberg very early saw the need to involve all countries and medical informatics groups in collaborative research and development. Beginning in the 1970s and 1980s, he started engaging with Drs. Hans Peterson in Stockholm (Sweden), Peter Reichertz in Hannover (Germany), Shigekoto Kaihara in Tokyo (Japan), and Jan van Bemmel in Rotterdam (The Netherlands). Lindberg encouraged and participated in many meetings leading up to the formation of the International Medical Informatics Association (IMIA) in 1980 and also promoted a deeper participation in transformative technological changes by medical librarians, nurse-informaticians, and indigenous people (Alaskan, Native American, and Hawaiian) through the healthcare-related informatics activities of the NLM once he became Director in 1984.

\section{Lindberg's Early Days and Work on Computers in Clinical Pathology}

Donald Allen Bror Lindberg was born on Sept. 21, 1933, in Brooklyn, New York. His father, Harry Bror Lindberg, was an architect and his mother, Frances Seeley (Little), who had been a teacher, was a homemaker. Donald Lindberg attended Amherst College, studying English, and then Biology, graduating Magna cum Laude in 1954. He then pursued medical studies at the College of Physicians and Surgeons of Columbia University, receiving the M.D. degree in 1958, followed by a residency in Pathology. As Kohane and Berg relate in their Retrospective in Science [20]: "Early on, Don recognized that medicine needed to be more data driven. During his residency training, his data-driven approach to medicine landed him in hot water with the surgery department when he showed that silicon used for cardiac bypass was causing extensive embolization and death. Only upon showing the surgeons the imaging data was he able to change their practice. This pattern was to be repeated throughout his career. At NLM, he used data to convince members of the US Congress and influential commercial stakeholders to better serve the public interest by, for example, requiring prior registration of expected outcomes for clinical trials."

In 1960 Donald Lindberg moved to the University of Missouri in Columbia to work in the Department of Pathology. He was engaged to run the clinical laboratories, to teach medical students and clinical pathology technologists while also running the Blood Bank and supporting the new open-heart surgery program. Besides all this, Lindberg was in charge of the clinical microbiology lab, of which he declared: "My first love was Microbiology. It was a well-run laboratory which always got the work done" [21]. However, he found a significant frustration in that bacteriological names were not spelled consistently or precisely in the hand-written reports on bacterial sensitivity to antibiotics, and the measurement of sensitivities in the reports was not standardized. Lindberg's whimsical sense of humor can be seen in a longer quote from the above reference: "This may have not actually impeded patient care, 
since the clinical house staff receiving them also did not spell with much precision. It did, however, allow the professor of Microbiology to hold me and the Pathology Department up to ridicule and contumely. This academic paragon did not, of course, know that the Record Room had at all times hundreds of lab reports on which the patient names did not even match the patient unit numbers. These were not allowed to be placed in the charts, and hence were lost forever. Misspelling was only one of our problems." [21, p.6]. To deal with this problem, Lindberg built a new machine which proved highly effective in helping practitioners select antibiotic therapies, though it required considerable time to analyze the manually-recorded data until he found that he could use a computer in the University's math department - but only for 15 minutes after midnight! This helped inspire Lindberg to build the first computer-based hospital laboratory system in the world, after having secured a dedicated IBM 1410 computer from the enlightened Dean Vernon Wilson. The system processed results from the microbiology laboratory, clinical chemistry, and hematology. Computer processing of the lab data enabled error detection and lab quality control, with some pattern recognition and diagnosis coming later. The pioneering lab system Lindberg developed became widely known nationally and internationally, was overwhelmed by visitors, and proved a showcase for IBM's computers in their role of making medicine more precise and scientific. Not surprisingly, it was the star of one of the company's promotional movies [22].

\section{Lindberg's First Syntheses: The Computer and Medical Care (1968), Editorship of Computers in Life Science Research (1974) and Paving the Way for Medical Al}

The medical success of the Missouri clinical laboratory system and its scientific and technological novelty led Dean Wilson to form a Medical Computer Program to test the question "Could computers contribute something to teaching, practice, and research in medicine?" Lindberg became its first director in 1962, and formed a multidisciplinary group with Gwilym Lodwick who headed the Department of Radiology, as well as engineers and mathematically savvy people from Pathology, Dietary, Surgery, and Medicine to help encourage "creative ventures in the professional services of the school and the hospital" [21]. During this time, Lindberg used the American Medical Association (AMA)'s Current Medical Terminology (CMT) tapes in the CONSIDER system 3 to search for differential diagnoses using the disease definitions matched against patient symptoms and findings [23]. He also worked on the automated analysis of electrocardiograms [24].

Lindberg participated in many national and international professional meetings on computers in medicine, including the first major international clinically-oriented meeting in 1966 on Automated Data Processing in Hospitals [25], organized by Tyjaeberg Hansen from the University of Copenhagen. It was held in Helsingor, Denmark (Elsinore in English), with its famous royal Kronborg castle, bestknown as the setting for Shakespeare's Hamlet. Lindberg presented papers on "Processing and Evaluation of Hospital Laboratory Data", and on "The computer and the hospital", where he described his experiences not only with the Missouri clinical laboratory system, but also other computer processes such as admissions, billing, and the recording of coded discharge diagnoses that he had worked on at the University of Missouri Hospital. These experiences provided him with the material to write his first book on the more general topic of Computers and Medical Care [26] published in 1968. The book was the first in English to focus primarily on how computers could help with the complex problems of clinical care, since prior or contemporaneous books on computers in medicine concentrated on topics involving either very general computational models related to biomedicine [27], or on medical decision-making with formal probabilistic models [28].

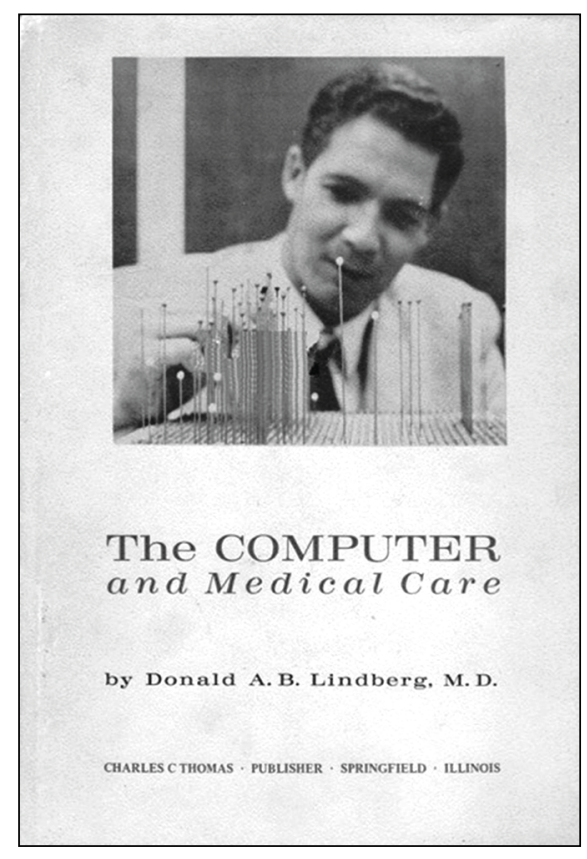

In his first book [26] Lindberg synthesized his experience with computers in medical care and commented on the future promise. He started by emphasizing the essential role played by computers in advancing research, teaching, and practice [Part I], followed by the importance of the data, or Significant Medical Record and its relationship with getting the Disease Nomenclature more precisely defined in both numerical and textual forms [Part II pp. 13-30]. In Part III, Lindberg focuses on Collecting Data in terms of choice of media and how physicians, nurses, patients, and clerical people can acquire it from a variety of sources, including physiological, psychological, imaging, and subjective reporting. In discussing "Data Volunteered by the Computer", Lindberg covered a wide range of subjects which have each proven important in the development of informatics - traditional hospital data, administrative decisions, "gratuitous laboratory studies" where he emphasizes the ease and cost-effectiveness of gathering whole panels of laboratory results, rather than the much more laborious and expensive one-at-a-time testing, physical examination, interrogatory history, and literature citations, all demonstrating the wide scope and understanding of clinical practices as they were being radically transformed by 
automation and computerization even in the 1960's. He was also explicitly recognizing the centrality of information as the binding factor in both computer and non-computer processing of patient data as well as hospital procedures and administrative data - though without using the word "informatics."

At the various meetings he attended, Lindberg met with many other pioneers in what was to become biomedical and healthcare informatics. These included his old friend Warner Slack who was at the University of Wisconsin at this time, developing a computer-based patient history record system, and with Octo Barnett, Howard Bleich, Morrie Collen, Lee Lusted, Homer Warner, Marion Ball, Francois Grémy, Tim DeDombal, Peter Reichertz, and Shigekoto Kaihara, among others. In the 1970's, Lindberg became the Director of Information Science at the University of Missouri School of Library Sciences, expanding his work into the activities of libraries, the organization and indexing of information, and the dissemination of biomedical knowledge.

In 1974, Lindberg chaired and gave the keynote address at the Federation of American Sciences for Experimental Biology (FASEB) Conference on the computer as a research tool in the life sciences, held in Aspen, Colorado [29]. These proceedings provide a good snapshot of the state-of-the-art of the early applications of networked computers for supporting life sciences and medical research through a program funded by the NIH Division of Research Resources (DRR). This program was responsible for launching the Artificial Intelligence (AI) knowledge-based approaches to biomedical problem solving, clinical interpretation and prediction, as well as early imaging and speech understanding research. Two of the AI projects, at Rutgers and Stanford Universities, were presented by Saul Amarel and Edward Feigenbaum, respectively, describing some of the earliest versions of the causal-network modeling of diseases in CASNET [30], and the rule-based approaches for treatment selection in infectious diseases in MYCIN [31], which had major impact on the development of expert systems and knowledge-based methods in the next generation of $\mathrm{AI}[32,33]$. Lindberg connected with the Stanford University Medical EXperimental computers for Artificial Intelligence in Med- icine (SUMEX-AIM) Resource, heading its Advisory Committee. Later in the decade, he initiated a collaboration with the Rutgers Research Resource on Computers in Biomedicine, and together with Kulikowski, Weiss, and Politakis developed a rheumatology knowledge base derived from the American Rheumatology Association clinical guidelines in collaboration with Gordon Sharp and Larry Kingsland which evolved into the AI/Rheum system $[34,35]$. Working with Stanford AI pioneer Edward Feigenbaum and Nobel Laureate Joshua Lederberg, Lindberg helped provide medical and scientific credibility to the new AI knowledge-based methods based on the above and other early AI in Medicine accomplishments [36], which helped secure both governmental and industrial support for the second generation of $\mathrm{AI}$ in biomedicine in the 1980's.

\section{Lindberg, Director of the US National Library of Medicine (1984 - 2015) Revolutionizing Biomedical Informatics Research, Practice, and Education}

Donald A.B. Lindberg was sworn in as the $19^{\text {th }}$ Director of the NLM in 1984, and immediately proceeded to work on updating the computing and information resources of the Library. The NLM was still primarily a central library distributing traditional publications (books and journals) to the network of medical libraries distributed across the USA. Twenty years earlier, in 1964, the MEDLARS (Medical Literature Analysis and Retrieval System) had pioneered computerization of biomedical bibliographic retrieval, and its online version, MEDLINE, first released in 1971 was the first large scale, computer-based search service publicly available via nationwide telecommunications networks.

During the 31 years of Lindberg's tenure, he transformed the NLM into the major world-wide driver of biomedical and clinical informatics research and development. He extended and expanded the services provided by the NLM through an open and international freely-accessible set of web-based systems, knowledge bases, and databases which have revolutionized the access to, and practice of, biomedical research and healthcare through advanced techniques of informatics. Lindberg supported all this by an in-house program of innovative research into medical and healthcare informatics methods and technologies, together with an external grant-funding program that actively and uniquely promoted and supported novel informatics research.

Lindberg understood from the start that the NLM needed to develop a long-term plan in order to convince the US Congress to appropriate the resources for the ambitious proposals he had in mind. As part of this, he envisioned developing the Unified Medical Language System to enable computer systems to behave as if they understood biomedical meaning, by providing resources for researchers and system developers to use in compensating for differences in the vocabularies employed in different electronic biomedical information sources and by different users [37, 38]. He was fortunate to recruit a very talented group of people who helped him in this and other projects, such as the Visible Human Project (VHP), where his background in pathology made him particularly sensitive to the need to provide the best annotated visual displays of and interfaces for accessing images of human anatomy online for medical educational purposes.

Together with advances in the computer representation of knowledge, data modeling, and the natural language processing methods underlying literature retrieval, analysis, and cross-indexing with other data and media, the UMLS helped revolutionize the systems for indexing the literature and making them accessible through MEDLINE (the online version of MEDLARS) and later the web-accessible and updated system PubMed Central. This had a major impact on the development of digital medical libraries [39] which have been instrumental in dramatically improving the speed with which biomedical discoveries can be publicized, shared, and lead to further discoveries. This in turn has scaled-up and made possible the rapid integration of the digital literature with data from the emerging massive databases of 
biomedical information and computational models, ranging in scale from the atomic/ molecular to population levels. These systems relied on what was being developed at the NLM in terms of increasingly sophisticated methods and technologies for natural language and text processing [40]. Research on language and the lexical facilities and resources needed to support biomedical information systems resulted in the development of ontology or knowledge representation frameworks [41] which have become ubiquitous for structuring everything from the anatomic knowledge underlying the Visible Human Project [42] to the complex metadata needed for genomic databases, as well as the clinical research resources such as those in ClinicalTrials.gov $[8,9]$ and the Visible Human Project, which for the first time made available for educational purposes full 3-D multimodal CT and MRI cross-sectional male and female datasets. Many major initiatives of the NLM in bioinformatics and genomic systems and databases have led to the genotype-phenotype studies linking clinical data from the electronic patient record to underlying genomic data [43]. Coordination through the National Center for Biotechnology Information (NCBI) resulted in streamlining systems which have proven essential to the development of translational and precision medicine [44].

\section{The Secret of Lindberg's Historical Success}

Donald A. B. Lindberg was an eloquent speaker and forceful exponent of his visions and plans. Much of his success rested on his talent in forging close relationships with a range of professionals: physicians, nurses, librarians, educators, publishers, economists, scientists, engineers, technologists, and influential members of the U.S. Congress, and successive Federal Administrations. A critical relationship was with U.S. Senator Claude Pepper, who was an enthusiastic supporter of the NLM and NIH, and helped appropriate the funding needed to advance Lindberg's long-term NLM Plans. The legislation and funding for setting up NCBI was largely due to Pepper's support. Later,
US Senator Bill Frist (R-TN), himself a physician, also strongly supported the NLM and helped inaugurate the first Internet-accessible search of MEDLINE in 1996. At the time, there were 8 million citations, whereas today they count over 30 million. The renowned cardiac and vascular surgeon Dr. Michael DeBakey was also influential in advising Dr. Lindberg while serving on the NLM's Boards. In addition, Vice-President Al Gore was a major force in providing federal support for the High Performance Computing and Communications (HPCC) initiative that Lindberg directed. He performed the first use of MEDLINE with the new software enabling free world-wide searches via PubMed in 1997.

At the professional level, Lindberg had great influence in bringing medical informatics as a new and essential discipline to be represented within the US National Academy of Sciences Institute of Medicine (now the National Academy of Medicine). He helped sponsor studies for the US government that had great impact on the movement towards universal adoption of Electronic Medical Records, as well as directing the foundational informatics and computational systems that enabled the Human Genome Project and the wide range of biomedical scientific investigations and discoveries that have revolutionized biomedicine and the practices of medicine, nursing, and public health worldwide over the past quarter of a century. From the broader perspective of helping people, Lindberg worked to "empower special populations with the reliable health information they need and deserve. This was on display in his hands-on approach to the design of an NLM exhibition on Native Voices: Native People's Concepts of Health and Illness, which showcased the cultures and healing ways of Alaska Natives, Native Americans, and Native Hawaiians"[45].

The international dimensions of Lindberg's success can be gauged by his influence on the early consolidation of IMIA and the many friendships and collaborations he shared with major leaders, including successive presidents, of the IMIA community. $\mathrm{He}$ was awarded many honors for his outstanding work and contributions, but remained modest in his acceptance and demeanor. He was a sailor at heart, who loved nothing more than exploring the waters of the Hudson River in his early life in New York, the Potomac River during his NLM tenure, or the Florida waters during his retirement on the Gulf Coast. With his life-long companion and wife Mary, a nurse who continues working with patients in hospice care, he shared a deep appreciation for one of the central ethical goals of medicine and nursing in alleviating the pain of those who suffer. Donald A.B. Lindberg was a truly outstanding leader who by his personal humanistic example strengthened both the altruistic vocations and the academic and clinical disciplines of biomedical and healthcare informatics.

\section{Acknowledgements}

The author wishes to express his gratitude to Michael J. Ackerman, Betsy L. Humphreys, and Alexa T. McCray for reading and commenting on an earlier version of this paper, suggesting many improvements. Any remaining shortcomings are entirely the author's responsibility.

\section{References}

1. Seelye KQ. Dr. Donald Lindberg, 85, Dies; Opened Medical Research to the World; New York Times, September 2, 2019. In: https://www.nytimes. com/2019/09/02/obituaries/dr-donald-lindbergdead.html.

2. Lindberg DAB, Siegel ER, Rapp BA, Wallingford KT, Wilson SR. Use of MEDLINE by physicians for clinical problem solving. J Am Med Assoc 1993;269(24):3124-9 (see also NIH: US National Library of Medicine, NCBI - Fact Sheet MEDLINE Journal Selection).

3. NIH: US National Library of Medicine, NCBI PubMed Help - Last Update July 25, 2019: https:// www.ncbi.nlm.nih.gov/books/NBK3827/\#pubmedhelp.PubMed_Quick_Start.

4. Maloney C, Sequeira E, Kelly C, Orris R, Beck J (5 December 2013). PubMed Central. National Center for Biotechnology Information (US).

5. NIH: US National Library of Medicine, The Visible Human Project Overview - Last Reviewed July 18, 2019: https:/www.nlm.nih.gov/research/visible/ visible_human.html.

6. Lindberg DAB, Humphreys BL, McCray AT. The Unified Medical Language System. Methods Inf Med 1993;32:281-91.

7. NIH: National Library of Medicine - TOXNET Toxicology Data Network -https://toxnet.nlm. nih.gov/ (to be migrated December 16, 2019 to PubChem, PubMed and Bookshelf.

8. McCray AT. Ide NC Design and implementation of a national clinical trials registry J Am Med Inform 
Assoc 2000;7:313-23.

9. McCray AT. Better access to information about clinical trials. Ann Intern Med 2000;133:609-13.

10. Goodman K, Adams S, Berner ES, Embi PJ, Hsiung R, Hurdle J, et al. AMIA's Code of Professional and Ethical Conduct. J Am Inform Assoc 2013 Jan-Feb;20(1):141-3.

11. The IMIA Code of Ethics: https://imia-medinfo. org/wp/wp-content/uploads/2015/07/IMIA-Codeof-Ethics-2016.pdf.

12. Wikipedia: https://en.wikipedia.org/wiki/National_Center_for_Biotechnology_Information.

13. Cohrs RJ, Martin T, Ghahramani P, Bidaut L, Higgins PJ, et al. Translational Medicine definition by the European Society for Translational Medicine. European Journal of Molecular and Clinical Medicine 2014;2(3):86-8. doi:10.1016/j. nhtm.2014.12.002.

14. NIH: US National Library of Medicine, ClinicalTrials.gov: https://clinicaltrials.gov/.

15. Collen MF. A History of Medical Informatics in the United States: 1950 to 1990. American Medical Informatics Association; 1995.

16. Salomon R, editor. MEDINFO 86 : Proceedings of the Fifth World Congress on Medical Informatics, Washington, October 26-30, 1986. Amsterdam: North Holland Press; 1986.

17. Lindberg DAB, West RT, Corn M. IAIMS: An Overview from the National Library of Medicine. Bull Med Libr Assoc 1992 Jul; 80(3):244-6.

18. Lindberg DAB. HPCC and the National Information Infrastructure: an overview. Bull Med Libr Assoc 1995 Jan;83(1):29-31.

19. Lindberg DAB. High performance computing and communications: the medical connection; In: Eleventh International Congress of the European Federation for Medical Informatics MIE 93. Tel Aviv, Israel: Freund Publishing House Ltd.;1993. p. 19-23.

20. Kohane I, Berg JM. Donald A B Lindberg (1933 - 2019). Science 2019;366(6461):37.

21. Lindberg DAB. In Praise of Computing In: Blum BI, Duncan K, editors. A History of Medical Informatics. ACM Press; 1990. p. 4-11.

22. Lindberg DAB. Computing and Divided Loyalties, In: Kulikowski CA Mihalas G Greenes R Park H-A Yacubsohn V, editors. International Medical
Informatics in the Transformation of Healthcare. Amsterda: IOS Press; 2020 (in press).

23. Lindberg DAB, Rowland LR, Buch CR Jr, Morse WF, Morse SS. CONSIDER: A computer program for medical instruction. In: Proc Ninth IBM Med Symposium, White Plains, NY; 1968.

24. Lindberg DAB, Amlinger PR. Automated analysis of the electrocardiogram. Missouri Med 1968;65:742-5.

25. Hansen T. Automated Data Processing in Hospitals, Copenhagen; 1967

26. Lindberg DAB. Computers and Medical Care. Springfield, IL: Charles Thomas; 1968.

27. Ledley RS. Uses of Computers in Biology and Medicine. New York: McGraw Hill; 1965.

28. Lusted L. Introduction to Medical Decision-Making. Springfield, IL: Charles Thomas; 1968.

29. Siler W, Lindberg DAB. Computers in Life Science Research. New York: FASEB, Plenum Press; 1975.

30. Weiss SM, Kulikowski CA, Safir A. Glaucoma Consultation by Computer. Comput Biol Med 1978;8(1):25-40

31. Shortliffe EH. Computer-Based Medical Consultations: MYCIN. New York: Elsevier/North Holland; 1976.

32. Buchanan BG, Shortliffe EH. Rule Based Expert Systems: The MYCIN Experiments of the Stanford Heuristic Programming Project. Reading, MA: Addison-Wesley; 1984.

33. Weiss SM, Kulikowski CA. A Practical Guide to Designing Expert Systems. Rowman \& Allanheld Publishers; 1984.

34. Lindberg DAB, Sharp GC, Kingsland LC III, Weiss SM, Hayes SP, Ueno H, et al. Computer-based rheumatology consultant. In: Lindberg DAB, Kaihara S, editors. Proc MEDINFO 80 Tokyo, Third World Conference on Medical Informatics. Amsterdam: North Holland Publishing Company; 1980. p. 1311-5.

35. Lindberg DAB, Sharp GC, Kay DR, Kingsland LC III, Roeseler GC, Kulikowski CA, et al. The expert consultant as teacher. Mobius 1983;3(2):30-6.

36. Clancey WJ, Shortliffe EH. Readings in Medical Artificial Intelligence: The First Decade. Reading, MA: Addison Wesley; 1984.

37. Lindberg DAB, Humphreys BL. Computer systems that understand medical meaning. In: Scherrer JR,
Cote RA, Mandil SH, editors. Proc IFIP-IMIA WG6 International Working Conference on Computerized Natural Medical Language Processing for Knowledge Representation, Geneva, Switzerland, 1988. North-Holland: Elsevier Science Publishers; 1989. p. 5-17.

38. McCray AT, Nelson SJ. The representation of meaning in the UMLS; Methods Inf Med 1995;34: 193-201.

39. Lindberg DAB, Humphreys BL. 2015-the future of medical libraries. N Engl J Med 2005;352(11):1067-70.

40. Bodenreider O, McCray AT. Exploring semantic groups through visual approaches J Biomed Inform 2003;414-32.

41. Vizenor L, Bodenreider O, Peters LB, McCray AT. Enhancing Biomedical Ontologies through Alignment of Semantic Relationships: Exploratory Approaches. Proc AMIA Fall Symp, 2006.

42. Ackerman MJ. The Visible Human Project of the National Library of Medicine. In: Degoulet P, Piemme TE, Rienhoff O, editors. MEDINFO 92. Proc Seventh World Congress on Medical Informatics. Amsterdam: North-Holland; 1992. p. 366-70.

43. Masys DR. Electronic Health Records and Genomic Medicine. In: Ginsburg GS, Willard HF, editors. Genomic and Precision Medicine. Third Edition: Foundations, Translation, and Implementation. Elsevier Academic Press; 2017.

44. Riley WT, Nilsen WJ, Manolio TA, Masys DR, Lauer M. News from the NIH: potential contributions of the behavioral and social sciences to the precision medicine initiative. Transl Behav Med 2015 Sep;5(3):243-6.

45. Anonymous. Lindberg: Anchors Aweigh -After 30 years at the helm, NLM Director Donald Lindberg MD sets sail for new waters. NIH Plus Spring 2015.

Correspondence to:

Casimir A. Kulikowski

Department of Computer Science

Rutgers - The State University of New Jersey

Piscataway, NJ 08855, USA

E-mail: kulikows@cs.rutgers.edu 